\title{
Composição química e aspecto superficial do slot de braquetes metálicos*
}

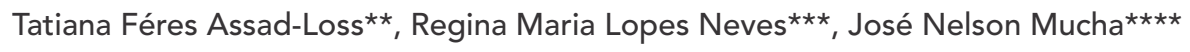

\begin{abstract}
Resumo
Objetivo: avaliar a composição química e rugosidade do fundo do slot de 90 braquetes metálicos divididos em 9 grupos: grupo 1- aço inoxidável (Equilibrium 2 - Dentaurum); grupo 2 - titânio (Equilibrium ti - Dentaurum); grupo 3- cromo-cobalto (Topic- Dentaurum); grupo 4 - aço inoxidável (Standard-TP Orthodontics); grupo 5 - aço inoxidável (Serie light - American Orthodontics); grupo 6 - aço inoxidável (Kirium Line - Abzil Lancer); grupo 7 - aço inoxidável livre de níquel (Monobloc-Morelli); grupo 8 - aço inoxidável (Convencional- Morelli) e grupo 9 - aço inoxidável livre de níquel (Monobloc Golden - Morelli). Metodologia: a composição química foi analisada pela Espectroscopia de Energia Dispersiva. A avaliação qualitativa do fundo do slot foi realizada através do MEV classificada de 0 a 8, correspondente às características da superfície. Resultados: composição química - grupo 1 = titânio puro; grupo 9 = recoberto por nitreto de titânio em 99,48\%; grupo 3 = cromo-cobalto; grupo 8 = aço inoxidável livre de níquel. Os demais grupos são compostos de aço inoxidável. Avaliação da superfície - grupo 1 = valor 2 (superfície mais polida); grupos 2, 5 e 7 = valor 3 (aspecto de polimento); grupos 3, 8 e 9 = valor 6 (menor polimento); grupo 4 = valor 6,5 (maior rugosidade) e o grupo 6 = valor 5 (características intermediárias de polimento). Conclusões: os braquetes metálicos são compostos de diferentes ligas e estão disponíveis com baixo conteúdo ou ausência de níquel. Os braquetes de titânio apresentaram polimento semelhante aos de aço inoxidável, porém os recobertos por nitreto de titânio e os de cromo-cobalto mostraram superfície mais irregular ou menos polida.
\end{abstract}

Palavras-chave: Braquetes metálicos. Composição química. Rugosidade do slot.

\section{INTRODUÇÃO}

O braquete Edgewise, proposto por Angle em 1928, é um dos componentes mais importantes do aparelho ortodôntico e sofreu inúmeras modificações ao longo dos anos.

Embora tenha havido grande evolução de materiais, formas e tipos, os braquetes metálicos continuam sendo os mais utilizados, devido às suas características físicas e propriedades mecânicas que foram intensamente pesquisadas ao longo dos anos. Entretanto, com o crescente número de pacientes com hipersensibilidade alérgica ao níquel presente nas ligas de aço inoxidável - material de eleição para confecção de braquetes - novos materiais metálicos começaram a ser utilizados para confecção dos mesmos ${ }^{1,12,26}$.

Parte da monografia apresentada ao curso de Especialização em Ortodontia da Universidade Federal Fluminense por Tatiana Féres Assad-Loss para obtenção do título de Especialista em Ortodontia.

** Especialista em Ortodontia pela Universidade Federal Fluminense - UFF, Niterói. Mestranda em Odontologia, UFF.

*** Mestre em Ortodontia pela UFRJ, Professora Adjunta de Ortodontia, Universidade Federal Fluminense, UFF, Niterói, RJ.

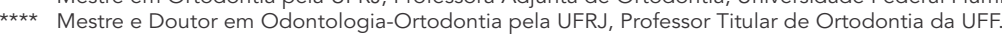


Entre os novos materiais, o titânio e o cromocobalto apresentam pouco ou nenhum níquel em sua composição podendo ser usado com segurança em pacientes alérgicos ${ }^{23}$. Entretanto, as características físicas que podem interferir nas propriedades mecânicas ainda não são totalmente conhecidas.

Uma característica física de grande interesse para a mecânica ortodôntica é a rugosidade das superfícies de contato do fio e do slot, uma vez que pode interferir na fricção superficial e, portanto, na mecânica de deslizamento ${ }^{14,21,29}$, além de influenciar no potencial corrosivo dos braquetes e fios ${ }^{16}$.

\section{Composição química e biocompatibilidade dos braquetes metálicos}

O tipo básico de aço inoxidável austenítico utilizado em braquetes é o 302 que contém 18\% de cromo, $8 \%$ de níquel e $0,15 \%$ de carbono. $\mathrm{O}$ aço inoxidável tipo 304 possui uma composição similar, com diferença apenas no conteúdo de carbono $(0,08 \%)$. Ambos os aço inoxidáveis 302 e 304 podem ser designados como aço inoxidável 18-8 ${ }^{1}$.

$\mathrm{O}$ aço austenítico que contém níquel como estabilizador primário inclui o tipo 316L (o L significa baixo conteúdo de carbono). Embora a adição de cromo tenha efeito na resistência à corrosão, o carbono, níquel, molibdênio e o nitrogênio são usados para aumentar esta propriedade. Como os átomos de níquel não são fortemente ligados, existe a probabilidade de liberação deste íon, levantando às questões de biocompatibilidade ${ }^{5}$.

Os braquetes de aço inoxidável possuem uma camada passiva constituída de $\mathrm{Cr}_{2} \mathrm{O}_{3}$, que promove a resistência à descoloração e à corrosão ${ }^{20}$, e caso seja rompida, a corrosão irá ocorrer ${ }^{1}$. Temperaturas durante a solda por chama ou elétrica $\left(400^{\circ} \mathrm{C}\right.$ a $900^{\circ} \mathrm{C}$ ) também podem causar corrosão ${ }^{1}$.

Os diferentes tipos de aço inoxidável austenítico apresentam composições diferentes, de acordo com o quadro $1^{2}$.

A corrosão de ligas ortodônticas ocorre no meio bucal, independente da estrutura da liga; defeitos durante a fabricação podem acelerar este proces$\mathrm{so}^{25}$. A corrosão em poros pode ser identificada em braquetes e fios, iniciando-se antes do aparelho ser colocado na boca, sendo encontrada em produtos novos e sem uso ${ }^{5}$.

A maior parte das reações alérgicas causadas por aparelho ortodôntico se deve ao níquel presente na liga de aço inoxidável. Cerca de 10\% da população feminina e $1 \%$ da população masculina é alérgica ao níquel. Apenas 30\% dos pacientes com alergia ao níquel desenvolvem reação a uma liga que contenha cromo ${ }^{1}$.

As concentrações de níquel e cromo na saliva não são alteradas por aparelhos fixos durante o primeiro mês de tratamento ${ }^{15}$ e testes cutâneos verificaram não haver diferença em relação à hipersensibilidade a metais presentes no aparelho ortodôntico, antes e após 2 meses da colocação do aparelho ${ }^{26}$.

Entretanto, a comparação do conteúdo de níquel de braquetes usados, reciclados e novos indicou diminuição do conteúdo de níquel nos usados e reciclados, e provável liberação de íons de níquel na cavidade bucal ${ }^{6}$. Do ponto de vista biológico, células da mucosa bucal expostas ao aparelho com altos níveis de níquel e cobalto mostraram alto dano ao DNA e pouca viabilidade ${ }^{7}$.

Devido às discussões sobre corrosão e sensibilidade ao níquel presente no aço inoxidável, foi desenvolvido o braquete de titânio, e este foi apresentado na Convenção Anual da Associação Americana, em 1995, e a patente foi obtida pela Companhia "Dentaurum". O braquete de titânio mostrou-se totalmente compativel com o ambiente bucal e superior em integridade estrutural quando comparado ao aço inoxidável ${ }^{13}$. Não apresenta o mesmo brilho do aço inoxidável, porém, não causaria dano ao paciente ${ }^{23}$.

A biocompatibilidade e resistência à corrosão dos braquetes de titânio se dão devido ao óxido estável que cobre o metal. Para tornar os braquetes de titânio mais aceitáveis pelos pacientes, estes foram revestidos por opacificadores. O nitreto de 


\begin{tabular}{|c|c|c|c|c|c|c|}
\hline & \multicolumn{6}{|c|}{ Composição } \\
\hline $\begin{array}{l}\text { Ti- } \\
\text { pos }\end{array}$ & $\begin{array}{c}\text { Carbono } \\
\%\end{array}$ & $\begin{array}{c}\text { Cromo } \\
\%\end{array}$ & $\begin{array}{c}\text { Níquel } \\
\%\end{array}$ & $\begin{array}{c}\text { Man- } \\
\text { ganês \% }\end{array}$ & $\begin{array}{c}\text { Sílicio } \\
\%\end{array}$ & Outros \% \\
\hline 301 & $0,08-0,20$ & $16-18$ & 6-8 & $2 \max$ & $1 \max$ & \\
\hline 302 & $0,08-0,20$ & $17-19$ & $8-10$ & $2 \max$ & $1 \max$ & \\
\hline $302 B$ & $0,08-0,20$ & $17-19$ & $8-10$ & & $2-3$ & \\
\hline 303 & $0,15 \max$ & $17-19$ & $8-10$ & 2 & 1 & $\begin{array}{c}\text { Mo } 0,6 \max \\
\text { P, S ou Se } \\
0,07 \text { min }\end{array}$ \\
\hline 304 & $0,08 \max$ & $18-20$ & $8-11$ & $2 \max$ & $1 \max$ & \\
\hline 308 & $0,08 \max$ & $19-21$ & $10-12$ & $2 \max$ & $1 \max$ & \\
\hline 309 & $0,20 \max$ & $22-24$ & $12-15$ & 2 & 1 & \\
\hline $309 \mathrm{~S}$ & $0,08 \max$ & $22-24$ & $12-15$ & 2 & 1 & \\
\hline 310 & $0,25 \max$ & $24-26$ & $19-22$ & $2 \max$ & $1,5 \max$ & \\
\hline 316 & $0,10 \max$ & $16-18$ & $10-14$ & 2 & 1 & Mo 2-3 \\
\hline 317 & $0,10 \max$ & $18-20$ & $11-14$ & $2 \max$ & $1 \max$ & Mo 3-4 \\
\hline 321 & $0,08 \max$ & 17-19 & 8-11 & $2 \max$ & 1 & Ti $5 X \mathrm{C}$ min \\
\hline 347 & $0,08 \max$ & $17-19$ & $9-12$ & $2 \max$ & $1 \max$ & $\begin{array}{c}\text { Cd10XC } \\
\text { min }\end{array}$ \\
\hline
\end{tabular}

Quadro 1 - Composição dos diferentes tipos de aço inoxidável austenític $0^{2} \mathrm{com}$ as respectivas porcentagens.

- max - porcentagem máxima do composto;

- min - porcentagem mínima do composto;

- XCmin - vezes o porcentagem do carbono no mínimo;

- Mo - molibdênio; P - fósforo; S - enxofre;

- Se - selênio; Ti - titânio; Cd - cádmio.

titânio, que tem aspecto de ouro, pode ser formado in situ e é coberto à vácuo, como o encontrado em braquetes de aço inoxidável. Embora tenha um aspecto agradável é muito duro, o que lhe confere menor coeficiente friccional ${ }^{23}$.

Os braquetes de titânio exibem propriedades mecânicas, resistência à corrosão e força de adesão, equivalentes, ou superiores, às de aço inoxidável. Não existem braquetes recobertos de titânio e sim coberturas como o nitreto de titânio que oferece pobre proteção contra liberação de níquel, ouro, e outros materiais preciosos como paládio ou platina, mas nenhum funciona como um braquete de titânio realmente ${ }^{4}$.

Embora o titânio puro tenha aproximadamente a mesma força de tensão que o aço inoxidável, esta liga é duas vezes mais resistente, o que é importante para a confecção de braquetes de tama- nho reduzido ${ }^{23}$.

Em relação à composição química, o titânio está presente somente após os primeiros 200 a $300 \AA$ da superfície do braquete. Esta fina superfície de deslizamento não é de titânio e sim uma mistura de hidrocarbonos, óxidos incluindo $\mathrm{TiO}_{2}$ (rutila - maior componente) e nitrogênio orgânico, formando uma camada passiva. Dentro do corpo do material, existe conteúdo intersticial suficiente, 3\% oxigênio, para enrijecer o braquete de titânio. Sendo assim, a superfície é mais suave que o corpo, o que é uma estratégia de confecção apropriada, para permitir que o corpo não sucumba às forças de contato do fio na extremidade das paredes do $s l o t^{20}$.

\section{Rugosidade do slot e fricção superficial}

Fricção ou atrito é a força que se opõe a toda ação que o ortodontista realiza para mover dentes ${ }^{19}$.

O que ocorre durante o deslizamento depende da interação entre braquete e fio e das características inerentes dos materiais ou ligas utilizadas. Quando a interação entre o par braquete/fio promove a liberação de força independente da angulação ou torque, ocorre a fricção clássica ou atrito entre as superfícies. Quando a liberação da força diminui, o deslizamento é progressivamente interrompido pelo mecanismo de ligação. Outros fenômenos, tais como dobras edentações e sulcos, podem também afetar o deslizamento e cessar o movimento. Certas características dos materiais (tais como: rugosidade, reentrâncias, engrenamento/travamento e componente de cisalhamento) podem também afetar o deslizamento entre fio e braquete $^{19}$.

O engrenamento, pela rugosidade, ocorre quando a aspereza de uma superfície do par braquete/ fio engata na outra superfície do par. Como resultado deste engrenamento, as superfícies se movem menos prontamente e assim aumenta a fricção ${ }^{19}$.

$\mathrm{O}$ atrito, embora independente da área macroscópica de contato aparente, é na verdade pro- 
porcional à área de contato verdadeira que pode ser detectada pelo Microscópio de Força Atômica $(\mathrm{MFA})^{23}$.

As rugosidades das superfícies podem afetar tanto o aspecto visual, provocando efeito antiestético do aparelho, quanto o coeficiente friccional, alterando a mecânica de deslizamento ${ }^{21}$.

O coeficiente friccional dos braquetes de titânio é comparável ao de aço inoxidável - devido à existência da camada passiva presente em ambos os materiais - sendo estes um substituto satisfatório aos de aço inoxidável, quando a mecânica de deslizamento for utilizada ${ }^{18,20}$.

Entretanto, existem divergências sobre as características, com os braquetes de titânio apresentando: menores forças friccionais - tanto estática quanto cinética - com o aumento da espessura do fio $^{13}$; textura superficial rugosa ${ }^{20}$; polimento no interior do slot de difícil execução, dificultando a mecânica de deslizamento ${ }^{29}$; e coloração mais acinzentada que o braquete de aço inoxidável ${ }^{20}$.

A avaliação da superfície do slot de braquetes e fios ortodônticos de ligas de titânio e aço inoxidável com o uso do MEV mostrou compatibilidade com os resultados de testes friccionais, sendo encontrado maiores valores friccionais para superfícies mais rugosas e irregulares ${ }^{13,16}$.

\section{Processo de confecção dos braquetes metálicos}

Os braquetes metálicos eram predominantemente fabricados por técnicas de usinagem e fundição. Entretanto, nos últimos anos, a moldagem por injeção metálica e sinterização tem sido o método de eleição. Descoberto e desenvolvido nos EUA no início de 1980, este método é especialmente adequado para confecção de pequenas peças $^{3,28,33}$.

Embora os braquetes produzidos por moldagem por injeção sejam de corpo único, livre de risco de corrosão associado ao par galvânico das ligas de soldagem com o aço inoxidável, a biocompatibilidade e resistência à corrosão pode ser diferente entre ligas com composições semelhantes ${ }^{34}$.

A moldagem por injeção de metal tem menor custo, devido à economia de material durante o ciclo de produção, pois o metal vazado e condutos adutores do metal podem ser reciclados e reutilizados, sendo considerada a tecnologia mais competitiva para a produção em larga quantidade. Usinagem é o processo mais caro, porque é estimado que $50 \%$ a $75 \%$ do metal utilizado sejam desperdiçados ${ }^{3}$.

A moldagem por injeção de metal permite o uso de qualquer liga para produção de braquetes ortodônticos. Independente das vantagens econômicas, o método de produção pode ter sérias implicações no desempenho clínico. $\mathrm{O}$ uso de novas ligas para a produção de braquetes por moldagem com injeção de metais de diferentes propriedades mecânicas pode afetar seu desempenho mecânico em condições clínicas ${ }^{33}$.

A resistência à fricção mostrou-se de 38\% a $44 \%$ menor nos braquetes sinterizados, quando comparados aos fundidos, devido à sua textura mais $\operatorname{lisa}^{28}$. Embora esta lisura possa ser obtida rotineiramente nos fios com a ajuda de troquéis de diamante, é um tanto difícil nivelar as superfícies internas de uma fenda, como a do slot do braquete ${ }^{24}$.

Objetivou-se, portanto, com este estudo, avaliar a composição química de 9 diferentes tipos de braquetes metálicos através da Espectroscopia de Energia Dispersiva (EDS), bem como avaliar as características da superfície do fundo do slot dos 9 tipos de braquetes metálicos através do Microscópio Eletrônico de Varredura (MEV).

\section{MATERIAL E MÉTODOS}

A amostra foi composta por 90 braquetes metálicos, divididos em 9 grupos de 10 braquetes cada, de acordo com o material, fabricante e especificações, como ilustrado no quadro 2.

\section{Composição química}

Antes da avaliação das superfícies do fundo do 
slot dos braquetes, estas superfícies foram limpas em banho ultrassônico por 5 minutos ${ }^{33}$.

A composição química da superfície do fundo do slot de cada tipo de braquete dos 9 grupos foi avaliada através do microscópio eletrônico de varredura (JEOL JSM-5800LV, IME, Rio de Janeiro, Brasil) com aumento de 500X com $20 \mathrm{kV}$ e $50 \mu \mathrm{m}$ de distância, através da espectroscopia de energia dispersiva (EDS).

\section{Característica da superfície do fundo do slot}

A superfície do fundo do slot dos 10 braquetes dos 9 grupos foi avaliada através do mesmo microscópio eletrônico de varredura, configurado da mesma forma, e foram obtidas 90 microfotografias digitais, impressas em papel fotográfico diretamente do MEV no momento de sua obtenção, nas dimensões de $10 \mathrm{~cm}$ x 7,5cm e organizadas em um álbum para posterior avaliação.
Cada uma das 90 microfotografias obtidas dos 9 grupos foi avaliada de acordo com as 8 características de superfície dispostas de acordo com a classificação descrita, a saber:

A) Presença de estrias ${ }^{9,16}$.

B) Aspecto mosqueado ou pintalgado ${ }^{31}$.

C) Presença de depressões, poros, sulcos ou

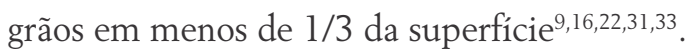

D) Presença de depressões, poros, sulcos ou grãos em 1/3 da superfície $e^{9,16,22,31,33}$.

E) Presença de depressões, poros ou sulcos ou grãos circunferenciais em $2 / 3$ da superfí$\mathrm{Cie}^{9,16,22,31,33}$.

F) Presença de depressões ou poros em toda a superfície ${ }^{9,16,22,31,33}$.

G) Aspecto faveolado ou alveolado

H) Presença de indentações ${ }^{22,33}$.

Um avaliador, sem o conhecimento de que grupo estava avaliando, previamente calibrado em

\begin{tabular}{|c|c|c|c|c|c|c|}
\hline grupo & material & modelo & slot & prescrição & confecção & fabricante \\
\hline 1 & aço inoxidável & Equilibrium 2 & $0,022^{\prime \prime} \times 0,030^{\prime \prime}$ & Roth & $\begin{array}{l}\text { moldagem } \\
\text { por injeção }\end{array}$ & Dentaurum ${ }^{\mathrm{a}}$ \\
\hline 2 & titânio & Equilibrium ti & $0,022^{\prime \prime} \times 0,030^{\prime \prime}$ & Roth & $\begin{array}{l}\text { moldagem } \\
\text { por injeção }\end{array}$ & Dentaurum ${ }^{a}$ \\
\hline 3 & cromo-cobalto & Topic & $0,022^{\prime \prime} \times 0,030^{\prime \prime}$ & Roth & $\begin{array}{l}\text { moldagem } \\
\text { por injeção }\end{array}$ & Dentaurum ${ }^{a}$ \\
\hline 4 & aço inoxidável & Standard & $0,022^{\prime \prime} \times 0,028^{\prime \prime}$ & Edgewise & $\begin{array}{l}\text { moldagem } \\
\text { por injeção }\end{array}$ & TP Orthodontics ${ }^{b}$ \\
\hline 5 & aço inoxidável & Serie light & $0,022^{\prime \prime} \times 0,028^{\prime \prime}$ & Edgewise & $\begin{array}{l}\text { moldagem } \\
\text { por injeção }\end{array}$ & $\begin{array}{l}\text { American } \\
\text { Orthodontics }\end{array}$ \\
\hline 6 & aço inoxidável & Kirium line & $0,022^{\prime \prime} \times 0,028^{\prime \prime}$ & Edgewise & $\begin{array}{l}\text { moldagem } \\
\text { por injeção }\end{array}$ & Abzil Lancer ${ }^{d}$ \\
\hline 7 & aço inoxidável & Monobloc & $0,022^{\prime \prime} \times 0,030^{\prime \prime}$ & Roth & $\begin{array}{l}\text { moldagem } \\
\text { por injeção }\end{array}$ & Morellie \\
\hline 8 & aço inoxidável & Convencional & $0,022^{\prime \prime} \times 0,030^{\prime \prime}$ & Roth & usinagem & Morellie \\
\hline 9 & aço inoxidável & Monobloc Golden & $0,022^{\prime \prime} \times 0,030^{\prime \prime}$ & Roth & $\begin{array}{l}\text { moldagem } \\
\text { por injeção }\end{array}$ & Morellie \\
\hline
\end{tabular}

Quadro 2 - Descrição dos grupos de acordo com o material, modelo, fabricante, tamanho do slot, tipo de prescrição e processo de confecção.

$\mathrm{a}=$ Ispringen, Alemanha.

$\mathrm{b}=$ La Porte, Indiana, EUA.

$\mathrm{c}=$ Sheboigan, WI, EUA.

$\mathrm{d}=$ São José do Rio Preto, SP, Brasil.

e = Sorocaba, SP, Brasil. 
relação às possíveis características a serem observadas nas fotografias das superfícies dos fundos de slot, dos 9 grupos de braquetes, avaliou as microfotografias em dois momentos distintos para eliminar possíveis erros intra-avaliador e quando foi encontrado disparidade entre as duas avaliações, foi solicitada uma terceira avaliação, que passou a ser a definitiva, descartando-se as anteriores.

Cada característica representava 1 ponto. A presença de mais de uma característica representava a adição de mais 1 ponto, correspondente às características a mais daquele grupo, ao valor final, podendo desta forma se obter valor de 0 a 8 para cada microfotografia.

Os dados obtidos foram dispostos em fichas previamente elaboradas para este propósito, para posterior computação e tabulação dos resultados. $\mathrm{O}$ valor mais freqüente entre os 10 braquetes de cada grupo ou a moda (medida utilizada para dados qualitativos) $)^{11}$ foi tomada como o valor representativo do grupo.
Os grupos que apresentaram o maior valor foram considerados os menos polidos, enquanto os que apresentaram menor valor, os mais polidos.

\section{RESULTADOS \\ Composição química}

A tabela 1 apresenta a porcentagem de cada composto presente nos braquetes de cada grupo.

Em relação aos grupos 1, 4 e 8, constituídos por braquetes de aço inoxidável, verificou-se que apresentam grande porcentagem de níquel em sua composição, enquanto os grupos 5 e 6 , também constituídos por braquetes de aço inoxidável, apresentam este elemento em porcentagem reduzida. Os grupos 7 e 9, constituídos por braquetes de aço inoxidável Niquel free, não apresentaram níquel em sua composição.

O gupo 2 apresentou em sua composição apenas o titânio e o grupo 9 apresentou 99,48\% deste elemento em sua superfície.

No grupo 3 verificou-se que os braquetes apre-

Tabela 1 - Porcentagem (\%) de cada composto químico por tipo de braquete avaliado.

\begin{tabular}{|c|c|c|c|c|c|c|c|c|c|}
\hline \multirow{2}{*}{ compostos } & \multicolumn{9}{|c|}{ grupos } \\
\hline & 1 & 2 & 3 & 4 & 5 & 6 & 7 & 8 & 9 \\
\hline cobalto $(\mathrm{CoO})$ & & & 62,36 & & & & & & \\
\hline $\operatorname{cromo}\left(\mathrm{Cr}_{2} \mathrm{O}_{3}\right)$ & 18,74 & & 32,50 & 18,84 & 24,97 & 18,11 & 18,28 & 19,54 & \\
\hline níquel (NiO) & 10,89 & & & 9,46 & 3,74 & 3,82 & & 8,05 & \\
\hline molibdênio( $\left.\mathrm{MoO}_{3}\right)$ & & & 3,57 & & & & & & \\
\hline silício $\left(\mathrm{SiO}_{2}\right)$ & 0,47 & & 0,93 & 0,93 & & & 0,40 & & \\
\hline ferro $\left(\mathrm{Fe}_{2} \mathrm{O}_{3}\right)$ & 67,29 & & 0,64 & 70,77 & 70,83 & 75,04 & 72,10 & 72,41 & 0,52 \\
\hline titânio $\left(\mathrm{TiO}_{2}\right)$ & & 100 & & & & & & & 99,48 \\
\hline cobre (CuO) & 2,13 & & & & & 3,03 & & & \\
\hline alumínio $\left(\mathrm{Al}_{2} \mathrm{O}_{3}\right)$ & 0,49 & & & & 0,46 & & & & \\
\hline manganês (Mn0) & & & & & & & 9,23 & & \\
\hline
\end{tabular}

Grupo 1 = aço inoxidável, Equilibrium, Roth, Dentaurum.

Grupo 2 = titânio, Equilibrium ti, Roth, Dentaurum.

Grupo 3 = cromo-cobalto, Topic, Roth, Dentaurum.

Grupo 4 = aço inoxidável, Standard, Edgewise Standard, TP Orthodontics.

Grupo 5 = aço inoxidável, Série light, Edgewise Standard, American Orthodontics.

Grupo 6 = aço inoxidável, Kirium line, Edgewise Standard, Abzil Lancer.

Grupo 7 = aço inoxidável, Monobloc, Edgewise Standard, Morelli.

Grupo 8 = aço inoxidável, Convencional, Roth, Morelli.

Grupo 9 = aço inoxidável, Monobloc Golden, Roth, Morelli. 
sentavam em sua composição, em sua maior parte, cobalto e cromo.

\section{Características da superfície do fundo do slot}

A tabela 2 apresenta o número de características presentes no fundo do slot de cada um dos 10 braquetes de cada um dos 9 grupos e o valor da moda (maior freqüência) para cada grupo.

Uma microfotografia, com aumento de 500x obtida ao MEV, de um corpo-de-prova de cada grupo está disposta na figura 1, para ilustrar as características observadas. A figura 1.1 corresponde à microfotografia de uma amostra do grupo $1 \mathrm{e}$ assim sucessivamente, nos 9 grupos.

Os grupos 1, 2, 5 e 7 apresentaram a superfície do fundo do slot mais homogênea e mais polida, sendo que o grupo 1 apresentou a maior lisura. Os grupos 3, 4, 8 e 9 apresentaram o maior número de características e, portanto, o maior valor e uma superfície menos polida. $O$ grupo 6 apresentou polimento superficial intermediário em relação aos valores encontrados para os demais grupos.

\section{DISCUSSÃO}

Avaliou-se no presente estudo a composição química de 9 tipos de braquetes metálicos de diferentes fabricantes disponíveis para a comercialização.

Os grupos 1, 4, 5, 6, 7 e 8 eram compostos por braquetes de aço inoxidável. Os braquetes dos grupos 1, 4 e 8 podem ser classificados como 18-8, sendo o tipo mais utilizado na confecção de braquetes ortodônticos ${ }^{1,2}$.

Os braquetes dos grupos 5 e 6 apresentam baixo conteúdo de níquel, o que sugere que sejam mais seguros em pacientes alérgicos a este material.

Outros autores ${ }^{8}$, empregando como método para a análise química o espectrômetro, encontraram para os braquetes Kirium Line da Abzil Lancer maior porcentagem de níquel $(8,32 \%)$ e cromo $(19,4 \%)$ que o encontrado no presente estudo

Tabela 2 - Número de características presentes na superfície do fundo do slot dos 10 braquetes de cada grupo e a moda (valor mais freqüente) obtida para cada grupo.

\begin{tabular}{|c|c|c|c|c|c|c|c|c|c|c|c|}
\hline \multirow{2}{*}{ Grupos } & \multicolumn{10}{|c|}{ Número de características presente na superfície do fundo do slot de cada braquete (10) } & \multirow{2}{*}{ Mod } \\
\hline & 1 & 2 & 3 & 4 & 5 & 6 & 7 & 8 & 9 & 10 & \\
\hline 1 & 1 & 2 & 2 & 2 & 1 & 2 & 3 & 2 & 2 & 2 & 2 \\
\hline 2 & 3 & 3 & 4 & 3 & 3 & 1 & 5 & 3 & 3 & 5 & 3 \\
\hline 3 & 6 & 6 & 6 & 6 & 6 & 6 & 6 & 6 & 6 & 6 & 6 \\
\hline 4 & 7 & 6 & 6 & 7 & 6 & 7 & 7 & 7 & 6 & 6 & 6,5 \\
\hline 5 & 4 & 3 & 5 & 3 & 4 & 3 & 4 & 2 & 3 & 3 & 3 \\
\hline 6 & 2 & 3 & 5 & 2 & 2 & 5 & 5 & 3 & 4 & 5 & 5 \\
\hline 7 & 3 & 3 & 3 & 3 & 5 & 3 & 3 & 4 & 4 & 3 & 3 \\
\hline 8 & 6 & 7 & 7 & 6 & 6 & 6 & 6 & 6 & 7 & 6 & 6 \\
\hline 9 & 6 & 7 & 2 & 6 & 6 & 7 & 6 & 7 & 6 & 7 & 6 \\
\hline
\end{tabular}

Grupo 1 = aço inoxidável, Equilibrium, Roth, Dentaurum.

Grupo 2 = titânio, Equilibrium ti, Roth, Dentaurum.

Grupo 3 = cromo-cobalto, Topic, Roth, Dentaurum.

Grupo 4 = aço inoxidável, Standard, Edgewise Standard, TP Orthodontics.

Grupo 5 = aço inoxidável, Série light, Edgewise Standard, American Orthodontics.

Grupo 6 = aço inoxidável, Kirium line, Edgewise Standard, Abzil Lancer.

Grupo 7 = aço inoxidável, Monobloc, Edgewise Standard, Morelli.

Grupo 8 = aço inoxidável, Convencional, Roth, Morelli.

Grupo 9 = aço inoxidável, Monobloc Golden, Roth, Morelli. 

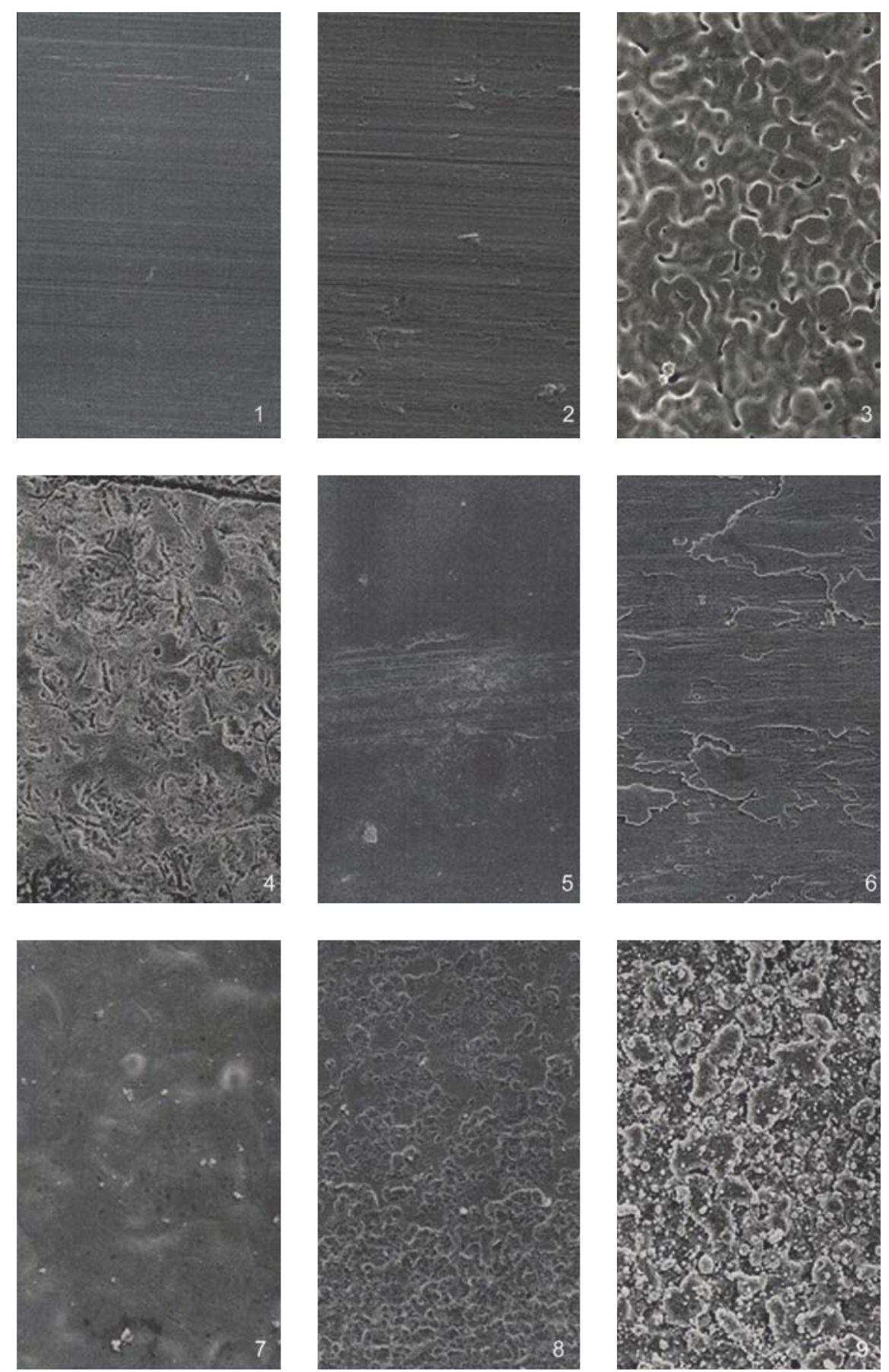

FIGURA 1 - Microfotografia da superfície do fundo do slot de um braquete de cada grupo, respectivamente, com aumento de 500X. 1.1) grupo $1=$ aço inoxidável, Equilibrium, Roth (Dentaurum). 1.2) grupo $2=$ titânio, Equilibrium ti, Roth (Dentaurum). 1.3) grupo $3=$ cromo-cobalto, Topic, Roth (Dentaurum). 1.4) grupo 4 = aço inoxidável, Standard, Edgewise Standard (TP Orthodontics). 1.5) grupo $5=$ aço inoxidável, Série light, Edgewise Standard (American Orthodontics). 1.6) grupo 6 = aço inoxidável, Kirium line, Edgewise Standard (Abzil Lancer). 1.7) grupo 7 = aço inoxidável, Monobloc, Edgewise Standard (Morelli). 1.8) grupo 8 = aço inoxidável, Convencional, Roth (Morelli). 1.9) grupo 9 = aço inoxidável, Monobloc Golden, Roth (Morelli). 
$(3,82 \%$ e $18,11 \%$ respectivamente). Entretanto, as porcentagens encontradas para estes elementos no braquete Convencional da Morelli, foram semelhantes às encontradas neste estudo.

Nos braquetes do grupo 7, de aço inoxidável do tipo Monobloc, não foi encontrado, neste trabalho, alguma quantidade de níquel em sua composição. Este resultado está de acordo com o especificado pelo fabricante na embalagem do produto (Niquel free) embora, ainda de acordo com o fabricante na especificação de segurança do produto, estes braquetes apresentem uma concentração máxima de $0,2 \%$ de níquel em sua composição, o que não pode ser detectado com a metodologia empregada neste estudo.

O grupo 2, formado pelos braquetes de titânio, mostrou-se composto por titânio puro, podendo também ser utilizado de forma segura em pacientes alérgicos ao níquel.

O grupo 3, composto pelos braquetes de cromo-cobalto, apresentou $32,5 \%$ de cromo e $62,36 \%$ de cobalto. Outros autores encontraram porcentagem semelhante para o cobalto de $62,5 \%$, porém, para o cromo, encontraram $30,6 \%$, aproximadamente $2 \%$ a menos que no presente estudo ${ }^{33}$. De acordo com o fabricante e relatado na embalagem do produto, os braquetes Topic contêm 63\% de cobalto e $30 \%$ de cromo, concentrações próximas aos valores encontrados no presente estudo.

O grupo 9 foi composto por braquetes de aço inoxidável Monobloc Golden. Estes braquetes apresentaram na composição da superfície 99,48\% do elemento químico titânio, podendo ser classificado como um braquete recoberto a vácuo por nitreto de titânio, que tem aspecto de ouro ${ }^{23}$. O relato do fabricante sobre a composição destes braquetes confirma este resultado. De acordo com o fabricante, eles seriam braquetes de aço inoxidável com uma concentração máxima de $0,2 \%$ de níquel em sua composição, recobertos por nitreto de titânio, em um processo no qual este composto é aplicado à superfície do braquete e se mantém retido por meios mecânicos, penetrando em po- rosidades previamente formadas para este fim. A espectroscopia de energia dispersiva (EDS) avalia apenas a composição química da superfície do braquete, desta forma, obteve-se neste estudo a composição da camada superficial de nitreto de titânio.

O espectrômetro é um aparelho que emite radiação em freqüência específica para cada elemento químico e, portanto, é capaz de identificar os elementos da liga como um todo e não só os presentes na superfície da liga, como o EDS ${ }^{8}$. Desta forma, este método deve ser empregado quando objetiva-se avaliar a liga de braquetes recobertos, como os braquetes do grupo 9 .

O braquete de titânio da amostra do presente estudo, o Equilibrium ti, se apresenta mais acinzentado e opaco em relação aos braquetes de aço inoxidável ${ }^{20,23}$.

O Microscópio Eletrônico de Varredura (MEV) tem sido utilizado em muitos estudos para avaliação da superfície dos braquetes, se mostrando adequado para avaliação qualitativa do polimento superficial e características destas superfícies ${ }^{13,16,17}$, 22,30,31,32,33. No presente estudo avaliou-se qualitativamente, através de microfotografias obtidas do MEV, a superfície do fundo do slot de braquetes metálicos de diferentes materiais e fabricantes.

O grupo 1, composto por braquetes de aço inoxidável Equilibrium 2, apresentou o maior polimento superficial em relação aos outros grupos.

O braquete 7 do grupo 1 apresentou a superfície semelhante às outra amostras, porém, poros puderam ser observados por toda a superfície ${ }^{5}$. O processo corrosivo pode se iniciar antes do aparelho ortodôntico ser colocado na boca. Embora seja mais freqüente em superfície extensivamente porosa, encontrada em produtos novos e sem uso ${ }^{5}$.

De acordo com Proffit, Field ${ }^{29}$ e Kusy et al. ${ }^{20}$, os braquetes de titânio seriam menos polidos que os de aço inoxidável, o que não foi verificado no presente estudo.

A avaliação da superfície através do MEV mostrou equivalência quando comparados os grupos 
1 e 2 (Equilibrium 2 e Equilibrium ti, respectivamente), embora no grupo 2 possam ser observadas endentações em poucas áreas da superfície ${ }^{4}$, provavelmente devido à forma de obtenção de braquetes de diferentes composição, a saber, aço inoxidável e titânio.

Em relação à avaliação da característica de superfície do material do braquete do grupo 3, Topic de cromo-cobalto, foi possível observar grãos de tamanho aumentado e uniforme ${ }^{33}$.

Embora não tenha sido observada relação suficiente entre fricção e dados obtidos no MEV pois seria necessário associar as características de superfície aos testes friccionais, para uma correlação entre rugosidade de superfície e aumento da fricção ${ }^{11}$ - é possível afirmar que a superfície do slot de braquetes menos polida interfere nas propriedades mecânicas e no potencial de corrosão ${ }^{10,13,16,18,20,24,26 \text {, }}$.

Alguns autores ${ }^{18,20}$ encontraram resultados semelhantes para os braquetes de aço e titânio nos testes friccionais, enquanto outros ${ }^{13}$ negam esta equivalência entre os materiais, afirmando que aço inoxidável e titânio possuem características friccionais distintas.

As imagens obtidas pelo MEV possuem caráter virtual, pois o que é visualizado na microfotografia é a transcodificação da energia emitida pelos elétrons do composto de forma bidimensiona ${ }^{10}$. Porém, o polimento de uma superfície é a média de altura entre picos (saliências) e depressões (vales) devendo ser quantitativamente mensurada de forma tridimensional ${ }^{24}$. A rugosidade de fios ortodônticos foi avaliada quantitativamente, utilizando-se o perfilômetro ${ }^{21,22,32}$. Entretanto, o fundo do slot do braquete impõe grande dificuldade para utilização do perfilômetro, por ser o fundo de uma cavidade.

A avaliação quantitativa da rugosidade do slot através do Microscópio de Força Atômica, assim como sua correlação com os resultados qualitativos obtidos no MEV, deve ser o foco de novos estudos.

Os braquetes confeccionados por processo de moldagem por injeção seriam mais polidos que os usinados e deveriam ser os preferidos em mecânica de deslizamento ${ }^{28}$. Porém, para Matasa ${ }^{23}$, a moldagem por injeção geraria superfícies mais ásperas que os braquetes obtidos pelo processo de corte com disco de diamante ou usinados.

No presente estudo, 8 dos 9 grupos foram compostos por braquetes confeccionados pelo processo de moldagem por injeção. Foi possível observar diferenças de polimento das superfícies dos diferentes grupos, possivelmente devido às características das ligas e devido ao número de etapas presente no processo de moldagem por injeção de metal.

A presença de poros pode estar relacionada a este processo, principalmente com a quantidade de aglutinante incorporada à mistura e que posteriormente é removida por aquecimento. $\mathrm{O}$ processo final de polimento também pode interferir nas características de superfície e deve ser realizado de modo a se obter uma superfície lisa e regular.

Entretanto, o processo de confecção dos braquetes não é a única variante que pode interferir nas características de superfície dos braquetes. Neste estudo foi observado que a composição das ligas que formam os braquetes difere entre si tanto na porcentagem quanto no tipo de elementos químicos presentes, o que influencia de modo decisivo nas características físicas dos materiais.

A comparação dos grupos 7 e 8, com processos de confecção distintos, mostrou que o grupo 7 (confeccionados por moldagem por injeção de metal e corpo único) apresentou superfície mais polida que seu equivalente, grupo 8 (composto por braquetes convencionais confeccionados pelo processo de usinagem ${ }^{28}$. Isto pode ter ocorrido devido à diferença na composição das ligas destes dois tipos de braquetes.

Deve-se enfatizar que embora o polimento da superfície do fundo do slot dos diferentes tipos e materiais dos braquetes testados sejam diferentes e que diversos estudos tenham sugerido a correlação positiva entre a diminuição do polimento da 
superfície e fricção superficial, para que se possa correlacionar tais dados é importante a realização do teste de resistência friccional. Desta forma, sugere-se a realização de novos estudos com estes objetivos.

\section{CONCLUSÕES}

De acordo com os resultados obtidos neste estudo, pode-se concluir que:

Os braquetes de aço inoxidável Equilibrium 2 (Dentaurum), Standard (TP Orthodontics), Série Light (American Orthodontics), Kirium Line (Abzil Lancer) e Convencional (Morelli) são compostos por diferentes elementos químicos tais como: cromo, níquel, silício, ferro, cobre e alumínio. Nos braquetes de aço inoxidável Monobloc (Morelli) não foi verificado, detectável através do EDS, níquel em sua composição. O braquete de titânio Equilibrium ti (Dentaurum) foi verificado como sendo composto por titânio puro. Os braquetes de cromo-cobalto Topic (Dentaurum) são contituídos destes elementos em sua composição.
Os braquetes de aço inoxidável Monobloc Golden (Morelli) são recobertos por nitreto de titânio.

Os braquetes de aço inoxidável Equilibrium 2 (Dentaurum), Série Light (American Orthodontics), Monobloc (Morelli) e de titânio Equilibrium ti (Dentaurum) apresentaram a superfície do fundo do slot com aspecto de melhor polimento. Os braquetes de cromo-cobalto Topic (Dentaurum), de aço inoxidável Standard (TP Orthodontics), Convencional e Monobloc Golden (Morelli) apresentaram a superfície menos polida. Os braquetes de aço inoxidável Kirium Line (Abzil Lancer) apresentaram características intermediárias de polimento.

\title{
Elemental composition and superficial aspect of metallic brackets slot
}

\begin{abstract}
Aim: To evaluate the elemental composition and the slot roughness of 90 metallic brackets divided into 9 groups: group 1 - stainless steel (Equilibrium 2 - Dentaurum); group 2 - titanium (Equilibrium ti - Dentaurum); group 3 chromium-cobalt (Topic - Dentaurum); group 4 - stainless steel (Standard - TP Orthodontics); group 5 - stainless steel (Serie light - American Orthodontics); group 6 - stainless steel (Kirium Line - Abzil Lancer); group 7 - stainless steel (Monobloc - Morelli); group 8 - stainless steel (Standard - Morelli) and group 9 - stainless steel (Monobloc Golden - Morelli). Methods: Elemental composition was evaluated using the Spectroscopy of Dispersive Energy. The qualitative slot surface evaluation was assessed using a 500X scanning electron microscope. The microphotography was classified according to surface characteristics in 0-8 values. Results: Elemental composition - group 1 $=100 \%$ titanium alloy; group $9=99,48 \%$ of titanium nitride coated. Group 3 = cobalt-chromium alloy; Group $8=$ nickel free stainless steel alloy; other groups stainless steel alloy. Surface evaluation - Group 1 = value 2 (smoothest surface); Groups 2, 5 and 7 =value 3 (smooth surface); Groups 3, 8 and 9 showed value 6 (roughness surface); Group $4=$ value 6,5 (the most roughness and irregular surface); and Group 6 has intermediate characteristics among the groups, with value 5. Conclusions: Metallic brackets were composed of different alloys and they were available with a small percentage or no nickel. The surface roughness was similar for both titanium and stainless steel, however the titanium nitride coated and cobalt-chromium showed an irregular and rough surface.
\end{abstract}

Key words: Metallic brackets. Elemental composition. Slot roughness. 


\section{REFERÊNCIAS}

1. ANUSAVICE, K. J. Phillips: materiais dentários. 10. ed. Rio de Janeiro: Guanabara Koogan, 1998.

2. CHIAVERINI, V. Aços-carbono e aços-liga: características gerais, tratamentos térmicos e principais tipos. São Paulo: Associação Brasileira de Metais, 1959.

3. COHRT, H. Metal injection molding. Mater. World., London, v. 7, p. $201-203,1999$

4. DEGUCHI, T. et al. Trial production of titanium orthodontic brackets fabricated by metal injection molding (MIM) with sinterizing. J. Dent. Res., Alexandria, v. 75, p. 1491-1496, 1996.

5. ELIADES, T.; ATHANASIOU, A. E. In vivo aging of orthodontic alloys: implications for corrosion potential, nickel release, and biocompatibility. Angle Orthod, Appleton, v. 72, no. 3, p. 222-237, Mar. 2002.

6. ELIADES, T. et al. Nickel content of as-received, retrieved, and recycled stainless steel brackets. Am. J. Orthod. Dentofacial Orthop., St. Louis, v. 122, no. 2, p. 217-220, Aug. 2002

7. FACCIONI, F. et al. In vivo study on metal release from fixed orthodontic appliances and DNA damage in oral mucosa cells Am. J. Orthod. Dentofacial Orthop., St. Louis, v. 124, no. 6, p. 687-694, Dec. 2003

8. GONTIJO, L. P.; MAZZIEIRO, E. T.; LANDRE JÚNIOR, J. Composição química e resistência mecânica da base de braquetes "Straight-Wire". Rev. Dental Press Ortodon. Ortop. Facial, Maringá, v. 9, n. 4, p. 52-59, jul./ago. 2004.

9. HUNT, N. P. et al. An investigation into the effect of polishing on surface hardness and corrosion of orthodontic archwires. Angle Orthod., Appleton, v. 69, no. 5, p. 433-440, Oct. 1999.

10. MICROSCÓPIO eletrônico de varredura. Disponível em: <http://www.degeo.ufop.br/laboratorios/microlab/mev.htm>. Acesso em: 15 jun. 2004.

11. RODRIGUES, P. C. Bioestatística. 3. ed. Rio de Janeiro: Eduff, 2002.

12. JANSON, G. R. P. et al. Nickel hypersensitivity reaction before, during, and after orthodontic therapy. Am. J. Orthod. Dentofacial Orthop., St. Louis, v. 113, no. 6, p. 655-660, June 1998.

13. KAPUR, R.; SINHA, P. K.; NANDA, R. S. Comparison of frictional resistance in titanium and stainless steel brackets. Am. J. Orthod. Dentofacial Orthop., St. Louis, v. 116, no. 3 , p. 271-274, Sept. 1999.

14. KAPUR, R.; SINHA, P. K.; NANDA, R. S. Frictional resistance in orthodontic brackets with repeated use. Am. J. Orthod. Dentofacial Orthop., St. Louis, v. 116, no. 4, p. 400-404, Oct. 1999.

15. KERUSO, H.; MOE, G.; HENSTEN-PETTERSEN. A. Salivary nickel and chromium in subjects with different types of fixed orthodontic appliances. Am. J. Orthod. Dentofacial Orthop., St. Louis, v. 111, no. 6, p. 595-598, June 1997.

16. KRISHNAN, V.; KUMAR, K. J. Mechanical properties and surface characteristics of three archwire alloys. Angle Orthod., Appleton, v. 74, no. 6, p. 825-831, Dec. 2004.

17. KRISHNAN, V.; KUMAR, K. J. Weld characteristics of orthodontic arch wire materials. Angle Orthod., Appleton, v. 74, no. 4, p. 533-538, Apr. 2004

18. KUSY, R. P.; O' GRADY, P. W. Evaluation of titanium brackets for orthodontic treatment: Part I. The active configuration. Am. J. Orthod. Dentofacial Orthop., St. Louis, v. 118, no. 6, p. 675-684, Dec. 2000.
19. KUSY, R. P.; WHITLEY, J. Q. Friction between different wire-bracket configurations and materials. Semin. Orthod., Philadelphia, v. 3, no. 3, p. 166-177, Sept. 1997.

20. KUSY, R. P. et al. Evaluation of titanium brackets for orthodontic treatment: Part I. The passive configuration. Am. J. Orthod. Dentofacial Orthop., St. Louis, v. 114, no. 5, p. 558-572, Nov. 1998.

21. KUSY, R. P. et al. Surface roughness of orthodontic archwires via laser spectroscopy. Angle Orthod, Appleton, v. 58, no. 1, p. 33-45, Jan. 1988

22. LEE, S. H.; CHANG, Y. Effects of recycling on the mechanical properties and the surface topography of nickel-titanium alloy wires. Am. J. Orthod. Dentofacial Orthop., St. Louis, v. 120, no. 6, p. 654-663, Dec. 2001

23. MATASA, C. G. Titanium, a metal with a future in orthodontics. The Orthodontic Materials Insider, v. 8, no. 3, p. 8, Sept. 1995. Disponível em: <http://www.orthocycle.com/insider/ insider_1995/september_1995.pdf>. Acesso em: 15 ago. 2004

24. MATASA, C. G. Encaixe do braquete examinado através do microscópio de força atômica (MFA). Rev. Clin. Ortodon. Dental Press, Maringá, v. 2, n. 5, p. 60-75, set./out. 1997.

25. MATASA, C. G. Biomateriais em Ortodontia. In: GRABER, T. M.; VANARSDALL, R. L. Ortodontia: princípios e técnicas atuais.

3. ed. Rio de Janeiro: Guanabara Koogan, 2002. p. 269-299.

26. MENEZES, L. M. et al. Hypersensitivity to metals in

Orthodontics. Am. J. Orthod. Dentofacial Orthop., St. Louis, v. 126, no. 1, p. 58-64, July 2004.

27. NISHIO, C. et al. In vitro evaluation of frictional forces between archwires and ceramic brackets. Am. J. Orthod. Dentofacial Orthop., St. Louis, v. 125, no. 1, p. 56-64, July 2004

28. OGATA, R. H. et al. Frictional resistances in stainless steel bracket-wire combinations with effects of vertical defections. Am. J. Orthod. Dentofacial Orthop., St. Louis, v. 109, no. 5, p. 535- 542, Nov. 1996.

29. PROFFIT, W. R.; FIELDS, H. W. Ortodontia contemporânea. 3. ed. Rio de Janeiro: Guanabara Koogan, 2002.

30. SAUNDERS, C. R.; KUSY, R. P. Surface topography and frictional characteristics of ceramic brackets. Am. J. Orthod. Dentofacial Orthop., St. Louis, v. 106, no. 1, p. 76-87, July 1994.

31. WALKER, M. P.; WHITE, R. J.; KULA, K. S. Effect of fluoride prophylactic agents on the mechanical properties of nickeltitanium-based orthodontic wires. Am. J. Orthod. Dentofacial Orthop., St. Louis, v. 127, no. 6, p. 662-669, June 2005.

32. WATANABE, I.; WATANABE, E. Surface changes induced by fluoride prophylactic agents on titanium-based orthodontic wires. Am. J. Orthod. Dentofacial Orthop., St. Louis, v. 123, no. 6, p. 653-656, June 2003.

33. ZINELIS, S. et al. Metallurgical characterization of orthodontic brackets produced by metal injection molding (MIM). Angle Orthod., Appleton, v. 75, no. 6, p. 1024-1031, Nov. 2005.

34. ZINELIS, S. et al. Elemental composition of brazing alloys in metallic orthodontic brackets. Angle Orthod., Appleton, v. 74, no. 3, p. 394-399, Mar. 2004

Endereço para correspondência

Tatiana Féres Assad-Loss

Rua: Santa Rosa 96 - Santa Rosa

CEP: 24.220-240 - Niterói / RJ

E-mail: tatianaassad@yahoo.com.br 